\title{
Insulina e glicose como moduladores do desenvolvimento de plântulas de milho doce (SuI)
}

\author{
Luiz Fernando Ganassali Oliveira Júnior ${ }^{1,5}$, Ricardo Bressan-Smith², Antônia Elenir Amâncio de Oliveira³, \\ Messias Gonzaga Pereira ${ }^{2}$, Luciana Belarmindo Silva ${ }^{3}$, Leandro Hespanhol Viana ${ }^{2}$ e Henrique Duarte Vieira ${ }^{4}$
}

Recebido em 3/11/2007. Aceito em 10/11/2008

\begin{abstract}
RESUMO - (Insulina e glicose como moduladores do desenvolvimento de plântulas de milho doce (Sul)). Durante a germinação e o desenvolvimento pós-germinativo de milho, o fluxo metabólico é intenso, ocorrendo síntese e degradação de açúcares (glicose, frutose e sacarose) e hidrólise de amido, além da redução da concentração do ácido abscísico (ABA). Acredita-se que altas concentrações de glicose exógena, promovam acúmulo de $\mathrm{ABA}$, proporcionando atraso na germinação e desenvolvimento de plântulas. Concentrações menores, por outro lado, podem ocasionar estímulo na germinação e desenvolvimento. Neste trabalho, foi observado que a glicose $(800 \mu \mathrm{M})$ estimulou a germinação e o desenvolvimento inicial de genótipo de milho comum e retardou, severa ou brandamente, genótipos de milho doce (su1), provavelmente devido às diferentes concentrações endógenas de glicose de cada genótipo. Foi visto, também, que a concentração de 1,2 rM de insulina foi capaz de estimular o maior desenvolvimento de genótipos de milho comum (UENF 506-8) e doce H43IN e nula para o genótipo doce HDC. Quando adicionada insulina e glicose ao meio, foi obtido efeito aditivo para o desenvolvimento. Esses resultados sugerem que a insulina e glicose apresentam forte influência na germinação e no desenvolvimento de sementes de milho.

Palavras-chave: desenvolvimento de plântulas, germinação de sementes, glicose, insulina, (Zea maize L.) milho doce (Su1)
\end{abstract}

ABSTRACT - (Insulin and glucose as modulators of the development of sweet corn seedling (Sul)). During germination and development of corn seeds the metabolic flow is intense, the synthesis and degradation of sugars (glucose, fructose and sucrose) and hydrolysis of starch, besides to the decrease in abscisic acid (ABA) concentration are some of the major events. High concentrations of exogenous glucose are believed to promote accumulation of ABA, causing delay in the germination and development of seedlings, while lower concentrations stimulated the germination and development. In our studies it was verified that $800 \mu \mathrm{M}$ glucose stimulated the germination and initial development of the common corn genotype and delayed severely or softly for sweet corn (su1) genotypes, probably due to different glucose endogenous concentrations of each genotype. It was also verified that $1.2 \mathrm{nM}$ insulin was capable to stimulate the development for the common corn and sweet H43IN genotypes and did not affect HDC sweet genotype development. These events may have happened due to metabolic differences in the mutants. When insulin and glucose were added to the medium, addictive effects on the development were observed. These results suggest that both insulin and glucose have strong influence on germination and development of corn seeds.

Key words: glucose, insulin, seed germination, seedling development, (Zea maize L.) sweet corn (Su1)

\section{Introdução}

A germinação de sementes pode ser dividida em três fases: a embebição; o aumento da atividade metabólica (divisão celular) e o crescimento (Bewley 1997). A embebição é um fenômeno físico no qual a absorção de água é impulsionada pelo potencial mátrico extremamente negativo da semente seca (Bewley \& Black 1985). Após a embebição, o desenvolvimento do embrião inicia-se pela expansão seguida de divisão, diferenciação celular e atividade de biossíntese e armazenamento de lipídeos e proteínas (Borisjuk et al. 1995), culminando com emergência radicular e crescimento da plântula. Durante a germinação, a ativação das rotas metabólicas e o crescimento inicial do embrião são fortemente regulados pelo ambiente e por sinais hormonais. Como exemplo, sabe-se que a luz estimula a germinação de sementes em diversas espécies e seus efeitos modulam o equilíbrio entre o incremento da biossíntese de giberelinas e decréscimo dos níveis do ácido abscísico (ABA) (Koornneef \& Karssen 1994; Toyomasu et al. 1994; Yang et al. 1995). Em contraste, a germinação é fortemente inibida pelo ABA, alta concentração de glicose ou disponibilidade limitada de água (Bewley \& Black 1985).
A relação entre açúcares e ABA na regulação da germinação de sementes ainda não está totalmente elucidada. É presumível que altos níveis de glicose exógena promovam o acúmulo de $\mathrm{ABA}$, o qual resultaria no atraso da germinação e do desenvolvimento da plântula. Arenas-Huertero et al. (2000) mostraram que a concentração de ABA em sementes de Arabidopsis sp. duplicou, depois de terem sido tratadas com altas concentrações de glicose ( $333 \mathrm{mM})$. Em contraste, a concentração endógena de ABA em sementes de Arabidopsis sp. não foi alterada depois de terem sido tratadas com baixos níveis de glicose $(27,7 \mathrm{mM})$ (Garciarrubio et al. 1997). Foi verificado também que, aplicando-se $167 \mathrm{mM}$ de glicose nas sementes, elas apresentaram redução da concentração do ABA e, conseqüentemente, maior germinação. Resultados semelhantes foram observados por Finkelstein \& Lynch (2000) após tratamento com diferentes concentrações de glicose ou frutose. Assim, foi observado que, para Arabdopsis sp., diferentes concentrações exógenas de glicose apresentaram efeitos distintos sobre o ABA e, conseqüentemente, sobre a germinação de sementes.

Sabe-se que as funções estruturais e metabólicas na célula requerem quantidades adequadas de carbono. Diante

\footnotetext{
Universidade Federal do Espírito Santo, Setor de Botânica, Vitória, ES, Brasil

2 Universidade Federal do Norte Fluminense, Laboratório de Melhoramento Genético Vegetal, Rio de Janeiro, RJ, Brasil

3 Universidade Federal do Norte Fluminense, Laboratório de Química e Função de Proteína e Peptídeo, Rio de Janeiro, RJ, Brasil

${ }_{4}$ Universidade Federal do Norte Fluminense, Laboratório de Fitotecnia, Rio de Janeiro, RJ, Brasil

5 Autor para correspondência: lfg@ pesquisador.cnpq.br
} 
disso, as plantas desenvolveram habilidade de perceber diferentes níveis internos de açúcar e de manter homeostase metabólica e iônica adequadas em cada fase do seu desenvolvimento (Price et al. 2003). Estes eventos estão fortemente sujeitos à regulação porque a biossíntese, $\mathrm{o}$ consumo e o seu armazenamento de açúcar podem ocorrer no mesmo órgão. As plantas modulam o controle da biossíntese de açúcar no tecido fonte e do consumo no tecido dreno. Porém, a complexa via regulatória é controlada por enzimas e diferentes intermediários que ocasionam mudanças de atividade celular dependente de açúcar (Smeekens 2000; Coruzzi \& Bush 2001; Coruzzi \& Zhou 2001). Muitas vezes, alguns processos podem ser medidos por níveis absolutos de um açúcar particular como a glicose (Borisjuk et al. 1998) ou a sacarose (Borisjuk et al. 2002), ao passo que outros podem ser modulados pelo fluxo de açúcares em eventos metabólicos da célula (Krapp et al. 1993).

Recentemente, proteínas com sequiência homóloga à insulina foram caracterizadas em sementes de Canavalia ensiformis (Oliveira et al. 1999) e de Vigna unguiculata (Venancio et al. 2003) e em folhas de Bauhinia variegata (Silva et al. 2002; Xavier Filho et al. 2003). A proteína relacionada imunologicamente à insulina também foi detectada em briófitas e em angiospermas, e até mesmo em cianobactérias (Silva et al. 2002; Xavier Filho et al. 2003). As evidências disponíveis apontam para o efeito estimulador da insulina sobre a germinação ou o crescimento, ou ambos, quando são fornecidas doses exógenas desse hormônio à semente. Não há informações precisas sobre o papel desta proteína no metabolismo de açúcares em plantas, como ocorre em animais. Embora não tenha sido feita análise detalhada em termos de transporte de açúcares e de atividade enzimática, no presente trabalho foi procurado demonstrar alguns efeitos da aplicação exógena de insulina e glicose no crescimento e no consumo de açúcares e amido do endosperma. Foi utilizado o mutante (Sul) de milho (Zea mays L.), que contrasta com o milho comum por apresentar deficiência enzimática que promove maior acúmulo de açúcares na semente, na expectativa de a insulina modular diferentemente os processos de biossíntese e degradação destes componentes.

\section{Material e métodos}

Foram utilizados dois genótipos de milho doce (H43IN e HDC) e um genótipo de milho comum (UENF506-8) (Zea mays L.).

As sementes de milho foram sanitizadas em solução de hipoclorito de sódio 5\% (v/v) por 6 horas. Em seguida, 75 sementes por tratamento, divididas em três repetições (25 sementes por repetição), foram embebidas entre duas folhas de papel (3 MM, Whatman, Clifton, NJ) com água ultra pura (controle), água mais insulina (concentração final 1,2 \\), água mais glicose (concentração final $800 \mu \mathrm{M}$ ) e glicose mais insulina (concentrações finais $1,2 \mathrm{\eta M}$ e $800 \mu \mathrm{M}$, respectivamente) e acondicionadas em estufa de crescimento, no escuro, por 100 horas, a $26-28{ }^{\circ} \mathrm{C}$, e umidade relativa de $85 \%$. Cem horas após a germinação, foram retiradas 15 plântulas para as análises.

As concentrações de insulina e glicose utilizadas foram estabelecidas a partir de ensaios realizados previamente com o genótipo UENF506-8, quando uma curva de germinação e crescimento foi construída, utilizando-se concentrações conhecidas de glicose $(200 \mu \mathrm{M}, 400 \mu \mathrm{M}$, $600 \mu \mathrm{M}, 800 \mu \mathrm{M}, 1 \mathrm{mM})$ e de insulina $(1,0 \mathrm{~m}, 1,2 \mathrm{\eta M}, 1,4 \mathrm{\eta M}$ e $\left.1,6 \prod \mathrm{M}\right)$. As concentrações de $800 \mu \mathrm{M}$ de glicose e 1,2 ¡p de insulina foram as que apresentaram melhores resultados.

Após 100 horas de germinação, a parte aérea e a parte radicular da plântula foram dissecadas manualmente, sendo a massa de matéria fresca e os comprimentos da raiz e da parte aérea determinados. Em seguida, os órgãos aéreos e radiculares foram pesados, congelados em $\mathrm{N}_{2}$ e acondicionados em freezer a $-80^{\circ} \mathrm{C}$ para determinações posteriores. A extração de açúcares solúveis e de amido foi feita a partir de tecidos congelados. Inicialmente, os mesmos foram macerados em $\mathrm{N}_{2}$ até a consistência de pó fino, sendo pesado $0,4 \mathrm{~g}$ e adicionados $800 \mu \mathrm{l}$ de etanol $80 \%$. O macerado foi homogeneizado em vortex por inversão de tubos e aquecidos em banho a $70{ }^{\circ} \mathrm{C}$, por 90 minutos. Decorrido esse tempo, as amostras foram centrifugadas a $13.600 \times \mathrm{g}$ por 15 minutos, sendo o sobrenadante, no qual se encontravam os açúcares solúveis, armazenado. Na etapa seguinte, foi feita a extração do amido, tendo sido o pellet ressuspendido em etanol $80 \%$, duas vezes, e o sobrenadante descartado para evitar qualquer interferência de resíduos de açúcares. Após a última lavagem, o pellet foi ressuspendido com $1000 \mu \mathrm{L}$ de $\mathrm{KOH} 0,2 \mathrm{~N}$, homogeneizado em vortex e incubado a $95{ }^{\circ} \mathrm{C}$, por 60 minutos. Em seguida, foram adicionados $140 \mu \mathrm{L}$ de ácido acético $1 \mathrm{~N}$ de forma a neutralizar o extrato. Por fim, o extrato foi centrifugado a $13.600 \times \mathrm{g}$, por 15 minutos, e o sobrenadante contendo o amido armazenado (Stitt et al. 1989).

As determinações de glicose, frutose e sacarose foram realizadas por análise enzimática (Stitt et al. 1989). Nos poços de uma placa de cultura de células foram adicionados amostra, água e tampão (imidazol $100 \mathrm{mM}, \mathrm{pH} 7,4, \mathrm{MgCl}_{2} 5 \mathrm{mM}$, NAD $2 \mathrm{mM}$, ATP $1 \mathrm{mM}$ ), além de $2 \mathrm{U}$ de glicose-6-fosfato desidrogenase $\left(\mathrm{G}_{6} \mathrm{PDH}\right)$ e $1,5 \mathrm{U}$ de hexoquinase para mensuração da glicose. Após o término da reação, foram adicionadas ao meio $3 \mathrm{U}$ de fosfoglicose isomerase para determinação de frutose. A sacarose foi determinada por adição de $5 \mathrm{U}$ de $\beta$-frutosidase, após a determinação de frutose.

Para determinação do amido foi seguido o mesmo protocolo de Stitt et al. (1989). A uma alíquota do extrato foram adicionados $35 \mu \mathrm{l}$ de tampão citrato, $\mathrm{pH} 4,6$, e $2 \mathrm{U}$ de amiloglicosidase, seguida de incubação a $60{ }^{\circ} \mathrm{C}$, por 45 minutos. Logo após, a amostra foi centrifugada a $13.600 \times \mathrm{g}, 2$ minutos, e retirada uma alíquota de $5 \mu \mathrm{l}$ de glicose resultante dessa reação para determinação de glicose, conforme descrito anteriormente.

O delineamento utilizado foi o inteiramente casualizado. Os dados obtidos foram provenientes de cinco repetições e submetidos às análises de variância e teste de média.

\section{Resultados e discussão}

Após 100 horas de germinação, $100 \%$ das sementes em todos os tratamentos apresentaram tanto crescimento radicular quanto da parte aérea e o endosperma tornou-se reduzido em função da translocação de carbono.

Maior desenvolvimento radicular foi verificado para o mutante $\mathrm{H} 43 \mathrm{IN}$ germinado em $\mathrm{H}_{2} \mathrm{O}$ após 100 horas, quando comparado ao genótipo comum (Tab. 1). Uma tendência para comportamento similar foi verificada para o mutante HDC. Provavelmente, este fato esteja relacionado aos maiores teores de glicose endógeno apresentados por esses genótipos de milho doce. Em Arabidopsis sp., foi relatado que a glicose exerce forte influência durante a germinação e desenvolvimento de sementes (Gibson et al. 1996; Garciarrubio et al. 1997; Arenas-Huertero et al. 2000), reduzindo o efeito do $\mathrm{ABA}$ e, conseqüentemente, acelerando a germinação e o desenvolvimento inicial (Price et al. 2003). Para que ocorra o desenvolvimento do embrião, a 
Tabela 1. Comprimento radicular e da parte aérea dos genótipos de milho comum e doce após 100 horas de germinação no escuro $(\mathrm{n}=15)$.

\begin{tabular}{|c|c|c|c|c|c|c|}
\hline \multirow[t]{2}{*}{ Tratamento } & \multicolumn{3}{|c|}{ Comprimento radicular $(\mathrm{cm})$} & \multicolumn{3}{|c|}{ Comprimento parte aérea $(\mathrm{cm})$} \\
\hline & UENF506-8 & H43IN & HDC & UENF506-8 & H43IN & $\mathrm{HDC}$ \\
\hline $\mathrm{H}_{2} \mathrm{O}$ & $10,83 \mathrm{cB}$ & $12,72 \mathrm{bA}$ & $11,63 \mathrm{aAB}$ & $3,73 \mathrm{bA}$ & $4,00 \mathrm{aA}$ & $2,60 \mathrm{aA}$ \\
\hline Insulina (1,2 rM) & $14,83 \mathrm{bA}$ & $15,73 \mathrm{aA}$ & $11,83 \mathrm{aB}$ & $4,00 \mathrm{abA}$ & $4,47 \mathrm{aA}$ & $2,17 \mathrm{aB}$ \\
\hline Glicose $(800 \mu \mathrm{M})$ & $14,33 \mathrm{bA}$ & $6,20 \mathrm{cC}$ & $11,17 \mathrm{aB}$ & $5,33 \mathrm{aA}$ & $1,50 \mathrm{bB}$ & $2,57 \mathrm{aB}$ \\
\hline Insulina + Glicose & $17,17 \mathrm{aA}$ & $16,33 \mathrm{aA}$ & $12,37 \mathrm{aB}$ & $4,77 \mathrm{abA}$ & $4,60 \mathrm{aA}$ & $2,30 \mathrm{aB}$ \\
\hline
\end{tabular}

Os valores representam médias obtidas. As médias seguidas pela mesma letra, minúscula na coluna e maiúscula na linha, não diferem entre si, a 5\% de probabilidade, pelo teste de Tukey.

concentração de $\mathrm{ABA}$ deve ser reduzida e o ácido giberélico secretado, ativando a expressão da á-amilase na camada de aleurona, promovendo a hidrólise do amido em glicose no endosperma. A glicose liberada pode ser fosforilada pela hexoquinase e convertida para sacarose no escutelo, que será translocada para o embrião (Buchanan et al. 2000). Numa segunda etapa, esses mesmos açúcares, principalmente a glicose, estariam sendo prontamente utilizados como fonte de carbono. Dessa forma, pressupõe-se que, pelo fato dos genótipos de milho doce possuírem maiores teores endógenos de glicose, tenha ocorrido maior germinação e desenvolvimento inicial de plântulas quando submetidos à solução de $\mathrm{H}_{2} \mathrm{O}$.

O genótipo UENF506-8 apresentou taxas maiores de desenvolvimento radicular nos tratamentos com insulina $(36,9 \%)$, glicose $(32,1 \%)$ e insulina + glicose $(58,5 \%)$, quando comparadas àquela do tratamento com $\mathrm{H}_{2} \mathrm{O}$ (Tab. 1), merecendo destaque o tratamento insulina + glicose. Presume-se que o bom desempenho em meio enriquecido com glicose e/ou insulina tenha ocorrido por se tratarem de substâncias que possam favorecer a translocação de solutos, como glicose e outros açúcares e, também, influenciar na regulação de enzimas, como a invertase, estando estes envolvidos diretamente com o metabolismo e transporte de açúcares ou afetando a relação fonte-dreno (Koch 1996; Jang \& Shenn 1997; Smeekens \& Rook 1997) e ao efeito antagônico do ABA. Os teores de glicose resultantes no endosperma após o desenvolvimento da plântula também foram superiores ao controle, comprovando a maior eficiência da insulina e/ou glicose adicionada ao meio durante a germinação (Tab. 3). Ou seja, para tal desenvolvimento a plântula requisitou menor quantidade de açúcares.

Quanto aos outros genótipos (H43IN e HDC), quando comparados ao UENF506-8 nos três tratamentos (insulina, glicose e insulina + glicose), de maneira geral, não foi observado o mesmo desenvolvimento (Tab. 1 e 2).
Provavelmente, o desenvolvimento inferior observado para estes genótipos tenha sido em função das concentrações de glicose e insulina utilizadas, já que foram ajustadas para o desenvolvimento ótimo do UENF506-8 (milho comum). Acredita-se que, pelo fato dos genótipos mutantes apresentarem altas concentrações de açúcares, o ideal seria fornecer concentrações menores para se ter desenvolvimento mais elevado. Tanto é provável que essa tenha sido uma das razões que, em presença de glicose, o genótipo H43IN apresentou menor crescimento e acúmulo de massa fresca (Tab. 1 e 2). Nesse genótipo, no tratamento com glicose, foi verificada uma inibição do crescimento radicular de 51,6\%. Foram observadas, também, maiores taxas de crescimento radicular nos tratamentos com insulina (31\%) e insulina + glicose (36\%), quando comparadas ao tratamento com $\mathrm{H}_{2} \mathrm{O}$. Já o genótipo HDC teve um comportamento indiferente diante de quase todos os tratamentos submetidos para todas as medidas (Tab. 1 e 2). Provavelmente, dada a sua concentração endógena de glicose e fatores genéticos ligados ao melhoramento deste híbrido.

O genótipo UENF506-8 (Tab.2) apresentou incremento da massa radicular nos tratamentos com insulina (50\%) e insulina + glicose $(58,3 \%)$. Quanto à massa da parte aérea, houve incremento de 78,5\% no tratamento com glicose, quando comparado ao tratamento com $\mathrm{H}_{2} \mathrm{O}$. Quanto ao genótipo H43IN, comportamentos idênticos para massa radicular e da parte aérea foram observados (Tab. 2) quando relacionados ao tratamento com glicose. Para os tratamentos insulina e insulina + glicose valores superiores foram verificados em função do estímulo exercido pela insulina.

Após 100 horas de germinação, os teores de glicose (Tab. 3) frutose (Tab. 4) e sacarose (Tab. 5) do UENF506-8 foram substancialmente inferiores àqueles dos demais genótipos, exceto para sacarose no tratamento com glicose, cujo valor não diferiu significativamente daquele detectado para HDC. Já o genótipo H43IN, quando submetido ao

Tabela 2. Massa radicular e da parte aérea dos genótipos de milho comum e doce após 100 horas de germinação no escuro (n = 15).

\begin{tabular}{|c|c|c|c|c|c|c|}
\hline \multirow[t]{2}{*}{ Tratamento } & \multicolumn{3}{|c|}{ Massa radicular (g) } & \multicolumn{3}{|c|}{ Massa da parte aérea (g) } \\
\hline & UENF506-8 & H43IN & HDC & UENF506-8 & H43IN & HDC \\
\hline $\mathrm{H}_{2} \mathrm{O}$ & $0,12 \mathrm{bA}$ & $0,14 \mathrm{bA}$ & $0,13 \mathrm{aA}$ & $0,14 \mathrm{bA}$ & $0,13 \mathrm{bA}$ & $0,07 \mathrm{aB}$ \\
\hline Insulina (1,2 çM) & $0,18 \mathrm{aAB}$ & $0,21 \mathrm{aA}$ & $0,16 \mathrm{aB}$ & $0,16 \mathrm{abA}$ & $0,18 \mathrm{aA}$ & $0,07 \mathrm{aB}$ \\
\hline Glicose $(800 \mu \mathrm{M})$ & $0,13 \mathrm{bA}$ & $0,08 \mathrm{cB}$ & $0,12 \mathrm{aAB}$ & $0,25 \mathrm{aA}$ & $0,04 \mathrm{cB}$ & $0,05 \mathrm{aB}$ \\
\hline Insulina + Glicose & $0,19 \mathrm{aAB}$ & $0,20 \mathrm{aA}$ & $0,15 \mathrm{aB}$ & $0,20 \mathrm{abA}$ & $0,19 \mathrm{aA}$ & $0,08 \mathrm{aB}$ \\
\hline
\end{tabular}

Os valores representam médias obtidas. As médias seguidas pela mesma letra, minúscula na coluna e maiúscula na linha, não diferem entre si, a $5 \%$ de probabilidade, pelo teste de Tukey. 
Tabela 3. Teor de glicose em genótipos de milho comum e doce após 100 horas de germinação no escuro $(n=5)$.

\begin{tabular}{lccc}
\hline Tratamento & \multicolumn{3}{c}{ Glicose $\left(\mu \mathrm{Mol} \mathrm{gMF}^{-1}\right)$} \\
\cline { 2 - 4 } & UENF506-8 & H43IN & HDC \\
\hline $\mathrm{H}_{2} \mathrm{O}$ & $187,3 \mathrm{cB}$ & $402,3 \mathrm{dA}$ & $392,9 \mathrm{aA}$ \\
Insulina $(1,2 \eta \mathrm{M})$ & $248,9 \mathrm{bB}$ & $438,7 \mathrm{cA}$ & $413,9 \mathrm{aA}$ \\
Glicose $(800 \mu \mathrm{M})$ & $235,5 \mathrm{bC}$ & $513,7 \mathrm{aA}$ & $429,4 \mathrm{aB}$ \\
Insulina + Glicose & $337,5 \mathrm{aC}$ & $468,8 \mathrm{bA}$ & $417,9 \mathrm{aB}$ \\
\hline
\end{tabular}

Os valores representam médias obtidas. As médias seguidas pela mesma letra, minúscula na coluna e maiúscula na linha, não diferem entre si, a $5 \%$ de probabilidade, pelo teste de Tukey.

Tabela 4. Teor de frutose em genótipos de milho comum e doce após 100 horas de germinação no escuro $(n=5)$.

\begin{tabular}{lccc}
\hline Tratamento & \multicolumn{3}{c}{ Frutose $(\mu$ Mol gMF-1 $)$} \\
\cline { 2 - 4 } & UENF506-8 & H43IN & HDC \\
\hline $\mathrm{H}_{2} \mathrm{O}$ & $180,6 \mathrm{bB}$ & $378,3 \mathrm{cA}$ & $332,1 \mathrm{aA}$ \\
Insulina $(1,2 \eta \mathrm{M})$ & $242,3 \mathrm{aC}$ & $453,3 \mathrm{bcA}$ & $345,4 \mathrm{aB}$ \\
Glicose $(800 \mu \mathrm{M})$ & $187,3 \mathrm{abC}$ & $526,4 \mathrm{aA}$ & $267,5 \mathrm{bB}$ \\
Insulina + Glicose & $209,1 \mathrm{abC}$ & $499,2 \mathrm{bA}$ & $325,0 \mathrm{aB}$ \\
\hline
\end{tabular}

Os valores representam médias obtidas. As médias seguidas pela mesma letra, minúscula na coluna e maiúscula na linha, não diferem entre si, a 5\% de probabilidade, pelo teste de Tukey.

Tabela 5. Teor de sacarose em genótipos de milho comum e doce após 100 horas de germinação no escuro $(n=5)$.

\begin{tabular}{lclc}
\hline Tratamento & \multicolumn{3}{c}{ Sacarose $\left(\mu \mathrm{Mol} \mathrm{gMF}^{-1}\right)$} \\
\cline { 2 - 4 } & UENF506-8 & H43IN & HDC \\
\hline $\mathrm{H}_{2} \mathrm{O}$ & $196,4 \mathrm{bB}$ & $405,4 \mathrm{cA}$ & $392,6 \mathrm{aA}$ \\
Insulina $(1,2 \eta \mathrm{M})$ & $209,1 \mathrm{bC}$ & $432,3 \mathrm{bcA}$ & $350,1 \mathrm{aB}$ \\
Glicose $(800 \mu \mathrm{M})$ & $301,3 \mathrm{aB}$ & $529,8 \mathrm{aA}$ & $356,2 \mathrm{aB}$ \\
Insulina + Glicose & $350,2 \mathrm{aBA}$ & $499,1 \mathrm{bA}$ & $347,9 \mathrm{aB}$ \\
\hline
\end{tabular}

Os valores representam médias obtidas. As médias seguidas pela mesma letra, minúscula na coluna e maiúscula na linha, não diferem entre si, a $5 \%$ de probabilidade, pelo teste de Tukey.

tratamento com glicose, apresentou teores de glicose, frutose e sacarose remanescentes no endosperma superiores aos demais tratamentos. Não por ter otimizado sua utilização, mas sim, em função do excesso de glicose (endógena + exógena) ter inibido o desenvolvimento da plântula e, dessa forma, não ter havido consumo. Isso vem a reforçar a hipótese de que a glicose, em concentrações altas, provocaria retardo na germinação e no desenvolvimento, conforme descrito por Arenas-Huertero et al. (2000).

$\mathrm{O}$ fato de a mesma concentração de glicose ter retardado apenas o desenvolvimento do mutante, e não do UENF506-8, é explicável, pois o mutante sul contém maiores teores de glicose que UENF506-8. Assim, quando $800 \mu \mathrm{M}$ de glicose foram adicionados às sementes, esta concentração excedeu àquela ideal e induziu aumento da concentração do $\mathrm{ABA}$, ocasionando o menor desenvolvimento, que resultou no menor consumo de açúcares e amido.

Quanto às sementes do genótipo UENF506-8, que foram germinadas na presença de glicose $(800 \mu \mathrm{M})$, o comprimento radicular foi igual ao tratamento com insulina. Contudo, foram observadas maiores taxas de crescimento da parte aérea, de massa da parte aérea e de concentração de açúcares (235,5 $\mu \mathrm{Mol} \mathrm{gMF}^{-1}$ glicose; $187,3 \mu \mathrm{Mol} \mathrm{gMF}^{-1}$ frutose e
301,3 $\mu \mathrm{Mol} \mathrm{gMF}^{-1}$ sacarose) no endosperma. Provavelmente, o maior desenvolvimento da parte aérea tenha sido em função das sementes germinadas com glicose apresentarem o embrião mais desenvolvido, pois segundo Weber et al. (1997), o maior teor de sacarose e o menor de glicose e frutose no endosperma sugerem maior desenvolvimento do embrião e, possivelmente, isso tenha levado ao maior desenvolvimento da parte aérea.

Os maiores teores de amido, independentemente do tratamento aplicado, foram observados no genótipo UENF506-8 (Tab. 6). Para esse genótipo, o valor numérico mais elevado foi verificado com o tratamento insulina + glicose. Já os teores de amido apresentados pelos genótipos HDC e H43IN não diferiram estatisticamente, mesmo quando comparados entre os diferentes tratamentos (Tab. 6).

Um dos tratamentos mais interessante para o crescimento foi o das sementes germinadas na presença de insulina + glicose (Tab.1). Nesse tratamento, o milho comum (UENF506-8) apresentou crescimento radicular superior ao tratamento com insulina ou com glicose, promovendo um efeito aditivo. Já para o mutante H43IN, considerando esse mesmo parâmetro, o tratamento insulina + glicose não ocasionou diferenças quando comparado ao tratamento com insulina e o tratamento com glicose proporcionou o menor crescimento. Estes resultados confirmam o efeito positivo da insulina sobre o desenvolvimento da plântula, mesmo quando aplicados teores de glicose além do necessário. È bem provável que, neste trabalho, a insulina tenha otimizado o excesso de glicose, que resultaria em inibição, e proporcionado incremento no desenvolvimento (Tab.1).

Os resultados apresentados pelos genótipos UENF506-8 e H43IN, quando as sementes foram germinadas na presença de insulina (1,2 ๆM), mostraram crescimento superior ao do tratamento com $\mathrm{H}_{2} \mathrm{O}$. É possível que, a insulina tenha proporcionado uma otimização na disponibilidade de solutos, bem como em seu transporte, promovendo um maior desenvolvimento. Com adição de insulina exógena ao meio, vários efeitos positivos foram observados no desenvolvimento pós-germinativo em sementes de Cirullus vulgaris (melancia), Helianthus annus (girassol) e Cucumis sativus (pepino), verificado pelo aumento da atividade de enzimas envolvidas na conversão de lipídeos armazenados em carboidratos (Goodman \& Davis 1992), estímulo da biossíntese de proteína ribosomal e desenvolvimento de plântulas de milho (Sanchéz de Jiménez et al. 1999) e de

Tabela 6. Teor de amido em genótipos de milho comum e doce após 100 horas de germinação no escuro $(n=5)$.

\begin{tabular}{lccr}
\hline Tratamento & \multicolumn{3}{c}{ Amido $\left(\mathrm{mg} \mathrm{gMF}^{-1}\right)$} \\
\cline { 2 - 4 } & UENF506-8 & \multicolumn{1}{c}{ H43IN } & \multicolumn{1}{c}{ HDC } \\
\hline $\mathrm{H}_{2} \mathrm{O}$ & $210,4 \mathrm{bA}$ & $94,9 \mathrm{aB}$ & $71,8 \mathrm{aB}$ \\
Insulina $(1,2 \eta \mathrm{M})$ & $280,9 \mathrm{abA}$ & $131,9 \mathrm{aB}$ & $88,1 \mathrm{aB}$ \\
Glicose $(800 \mu \mathrm{M})$ & $255,5 \mathrm{bA}$ & $137,2 \mathrm{aB}$ & $101,6 \mathrm{aB}$ \\
Insulina + Glicose & $351,4 \mathrm{aA}$ & $137,8 \mathrm{aB}$ & $106,8 \mathrm{aB}$ \\
\hline
\end{tabular}

Os valores representam médias obtidas. As médias seguidas pela mesma letra, minúscula na coluna e maiúscula na linha, não diferem entre si, a 5\% de probabilidade, pelo teste de Tukey. 
cevada (Csaba \& Pal 1982). Embora seu papel ainda não tenha sido desvendado, supõe-se que a insulina induza a ativação de uma via de translocação em células do milho (Flores et al. 2001) que, seletivamente, regula a translocação de glicose para o maior desenvolvimento. Flores et al.(2001) isolaram uma proteína de $20 \mathrm{kDa}$, um fator de crescimento do tipo insulina (do inglês, "insulin-like growth factor"- IGF), denominada de ZmIGF, que em contato com sementes de milho em solução, ocasionou aumento significativo da velocidade de germinação e do crescimento de plântulas.

Tanto a insulina quanto a glicose atuaram de forma decisiva na germinação e desenvolvimento de plântulas de milho, mostrando efeitos diferenciados quando comparadas plântulas de milho doce e comum. Essas diferenças podem ser resultantes da concentração endógena de glicose, sugerindo, assim, uma função na regulação do ácido abscísico. Todavia, estudos adicionais são necessários a fim de explicitar a forma como a insulina está envolvida com o metabolismo de açúcares, seja otimizando o transporte de solutos, como glicose, frutose ou sacarose, seja atuando em pontos específicos da rota metabólica.

\section{Referências bibliográficas}

Arenas-Huertero, F.; Arroyo, A.; Zhou, L.; Sheen, J. \& Leon, P. 2000. Analysis of Arabidopsis glucose insensitive mutants, gin5 and gin6, reveals a central role of the plant hormone ABA in the regulation of plant vegetative development by sugar. Genes \& Development 14: 2085-2096.

Bewley, J.D. 1997. Seed germination and dormancy. Plant Cell 9: 1055-1066.

Bewley, J.D. \& Black, M. 1985. Seeds: physiology of development and germination. Plenum Press 73: 115-120.

Borisjuk, L.; Weber, H.; Panitz, R.; Manteuffel, R. \& Wobus U. 1995. Embryogenesis of Vicia faba L.: histodifferentiation in relation to starch and storage protein synthesis. Journal of Plant Physiology 147: 203-218.

Borisjuk, L.; Walenta, S.; Weber, H.; Mueller-Klieser, W. \& Wobus, U. 1998. High-resolution histographical mapping of glucose concentrations in developing cotyledons of Vicia faba in relation to mitotic activity and storage processes: glucose as a possible developmental trigger. Plant Journal 15: 583-591.

Borisjuk, L.; Wang, T.L.; Rolletscheck, H.; Wobus, U. \& Weber H. 2002. A pea seed mutant affected in the differentiation of the embryonic epidermis is impaired in embryo growth and seed maturation. Development 129: 1595-1607.

Buchanan, B.; Gruissem, W. \& Jones, R. 2000. Biochemistry \& Molecular Biology of Plants. American Society of Plant Physiologists.

Coruzzi, G. \& Bush, D.R. 2001. Nitrogen and carbon nutrient and metabolite signaling in plants. Plant Physiology 125: 61-64.

Coruzzi, G.M. \& Zhou, L. 2001. Carbon and nitrogen sensing and signaling in plants: emerging "matrix effects". Current Opinion in Plant Biology 4: 247-253.

Csaba, G. \& Pa'1 K. 1982. Effects of insulin, triiodothyronine, and serotonin on plant seed development. Protoplasm 110: 20-22.

Finkelstein, R.R. \& Lynch, T.J. 2000. Abscisic acid inhibition of radicle emergence but not seedling growth is suppressed by sugars. Plant Physiology 122: 1179-1186.

Flores, G.C.; Aguilar, R.; Reyes de la Cruz, H.; Albores, M. \& Sánchez de Jiménez, E. 2001. A maize insulin-like growth factor signals to a transduction pathway that regulates protein synthesis in maize. The Biochemical Journal 358: 95-100.
Garciarrubio, A.; Legaria, J.P. \& Covarrubias, A.A. 1997. Abscisic acid inhibits germination of mature Arabidopsis seeds by limiting the availability of energy and nutrients. Planta 203: 182-187.

Gibson, S.; Kincaid, M.S.; Kuo, M.Y. \& Ciau, N. 1996. Sugar insensitive (SIS) mutants of Arabidopsis thaliana (abstract no. 800). Plant Physiology 111: S-169.

Goodman, D.B.P. \& Davis, W.L. 1992. Insulin accelerates the postgerminative development of several fat-storing seeds. Biochemical and Biophysical Research Communications 190: $440-446$.

Jang, J. \& Sheen, J. 1997. Sugar sensing in higher plants. Trends in Plant Science 2: 208-214

Koch, K.E. 1996. Carbohydrate-modulated gene expression in plants. Annual Review of Plant Physiology and Plant Molecular Biology 47: 509-540.

Koornneef, M. \& Karssen, C.M. 1994. Seed Dormancy and Germination. Pp. 313-334. In: E.M. Meyerowitz \& C.R. Somerville (eds.). Arabidopsis. New York, Cold Spring Harbor Laboratory Press.

Krapp, A.; Hofmann, B.; Schafer, C. \& Stitt, M. 1993. Regulation of the expression of $\mathrm{rbcS}$ and other photosynthetic genes by carbohydrates: a mechanism for the sink regulation of photosynthesis. Plant Journal 3: 817-828.

Oliveira, A.E.A.; Machado, O.L.T.; Gomes, V.M.; Xavier Neto, J.; Pereira, A.C.; Vieira, J.G.H.; Fernandes, K.V.S. \& Xavier Filho, J. 1999. Jack bean seed coat contains a protein with complete sequence homology to bovine insulin. Protein and Peptide Letters 6: 15-21.

Price, J.; Tsai-Chi, L.; Kang, S.G.; Na, J.K. \& Jyan-Chyun, J. 2003. Mechanisms of glucose signaling during germination of Arabidopsis. Plant Physiology 132: 1424-1438.

Sanchez de Jiménez, E.; Beltrán-Penã \& Ortiz-Lópes, A. 1999. Insulin-stimulated ribossomal protein synthesis in maize embrionic axis during germination. Physiologia Plantarum 105: $148-154$

Silva, L.B.; Santos, S.S.S.; Azevedo, C.R.; Cruz, M.A.L.; Venâncio, T.M.; Cavalcante, C.P.; Uchoa, A.F.; Astolfi Filho, S.; Oliveira, A.E.A.; Fernandes, K.V.S. \& Xavier Filho, J. 2002. The leaves of green plants as well as a cyanobacterium, a red alga, and fungi contain insulin-like antigens. Brazilian Journal of Medical and Biological Research 35: 297-303.

Smeekens, S. 2000. Sugar-induced signal transduction in plants. Annual Review of Plant Physiology and Plant Molecular Biology 51: 49-81.

Smeekens, S. \& Rook, F. 1997. Sugar sensing and sugar-mediated signal transduction in plants. Plant Physiology 115: 7-13.

Stitt, M.; Lilley, R.M.C.; Gerhardt, R. \& Heldt, H.W. 1989. Metabolite levels in specific cells and subcellular compartments of plant leaves. Methods in Enzymology 174: 518-552.

Toyomasu, T.; Yamane, H.; Murofushi, N. \& Inoue, Y. 1994. Effects of exogenously applied gibberellin and red light on the endogenous levels of abscisic acid in photoblastic lettuce seeds. Plant and Cell Physiology 35: 127-129.

Venâncio, T.M.; Silva, L.B.; Oliveira, A.E.A.; Fernandes, K.V.S. \& Xavier Filho, J. 2003. A protein with sequence homology to bovine insulin is present in the legume Vigna unguiculata (cowpea). Brazilian Journal of Medical and Biological Research 36: 1167-1173.

Weber, H.; Borisjuk, L. \& Wobus, U. 1997. Sugar import and metabolism during seed development. Trends in Plant Science 2: $169-174$.

Xavier Filho, J.; Oliveira, A.E.A.; Silva, L.B.; Azevedo, C.R.; Venâncio, T.M.; Machado, O.L.T.; Oliva, M.L.; Fernandes, K.V.S. \& Xavier Neto, J. 2003. Plant insulin or glucokinin: a conflicting issue. Brazilian Journal of Plant Physiology 15: 67-78.

Yang, Y.Y.; Nagatani, A.; Zhao, Y.J.; Kang, B.J.; Kendrick, R.E. \& Kamiya, Y. 1995. Effects of gibberellins on seed germination of phytochrome-deficient mutants of Arabidopsis thaliana. Plant and Cell Physiology 36: 1205-1211. 